\title{
Evidence From Data Analysis, Fifteen Developed Countries and the United States Home Prices Increase Between 1990 to 2006 Result of Advancement In Technology, Worldwide Economic Collapse and Great Recession Result of False Information by Media and Economic Policy Failures: Walters Real Estate Bubble Impossibility Price Transparency Theory, Real Estate Bubble Is Impossible, An End to Economic Policies Based on False Information
}

\author{
Eddison T. Walters ${ }^{1}$ \\ ${ }^{1}$ Walters Global Business Resources LLC, United States \\ Correspondence: Dr. Eddison T. Walters, Walters Global Business Resources LLC, 170 NE 2nd Street \#4065 \\ Boca Raton, FL 33429, United States.
}

Received: September 28, 2020

Accepted: October 26, 2020

Online Published: October 27, 2020

doi:10.5539/ibr.v13n11p114

URL: https://doi.org/10.5539/ibr.v13n11p114

\begin{abstract}
Based on the findings of the current study, policymakers must take a hard look at the media and themselves, because the world can no longer blame the subprime mortgage industry for causing the Global Financial Crisis of 2007 and 2008. The public must demand answers from the media and policymakers explaining how an economic crisis that could have been avoided resulted in the collapse of the global economy. The lack of evidence supporting the theory of a financial bubble and a real estate bubble called for further investigation of factors leading to the Global Financial Crisis of 2007 and 2008. Evidence presented from data analysis in Walters (2018) suggested no financial bubble existed in developed or developing countries around the world, preceding the Global Financial Crisis of 2007 and 2008. Based on data analysis in Walters (2018) the evidence also suggested, the lasting effect of economic policies in response to the Global Financial Crisis of 2007 and 2008 for both developed and developing countries around the world, had no significant impact on the financial sector but pointed to a lack of economic growth. The findings raised significant questions about the existence of a real estate bubble in both developed and developing countries. Evidence from data analysis presented in Walters and Djokic (2019) suggested the existence of a real estate bubble in the United States real estate market preceding the Global Financial Crisis of 2007 and 2008 was a false conclusion. Data analysis in Walters (2019) resulted in, 0.989 Adjusted R-square, 194.041 Mean Dependent Variable, 5.908 Square Error of Regression, 488.726 Sum-of- Square Residual, and 0.00000 Probability (F-statistic), for correlation between the independent variable representing advancement in technology, and the dependent variable representing home purchase price in the United States preceding the Global Financial Crisis of 2007 and 2008. The findings in Walters (2019) concluded the rapid increase in home purchase price in the United States real estate market, was due to increased demand for homes from the adaptation of advancement in technology in the real estate and mortgage industries. The current study expanded the investigation of the growth in home purchase price to fifteen developed countries around the world, building on the findings of previous research by the current researcher. The researcher in the current study concluded, the existence of significant and near-perfect correlation in many cases, between the dependent variable representing growth in home purchase price, and the independent variable representing advancement in technology. The analysis was based on data analyzed from fifteen developed countries around the world, which was collected between 1990 and 2006. The data analysis included home purchase price data from, Canada, United Kingdom, Denmark, Finland, France, Italy, New Zealand, Sweden, Netherlands, Australia, Ireland, Belgium, Norway, Spain, and Portugal. Data preceding the Global Financial
\end{abstract}


Crisis of 2007 and 2008 were analyzed in the current study. The researcher in the current study concluded the existence of overwhelming evidence suggesting advancement in technology was responsible for the rapid increase in home prices in developed countries around the world preceding the Global Financial Crisis of 2007 and 2008. The result of data analysis in the current study provided further confirmation of the accuracy of former Federal Reserve Board Chairmen, Alan Greenspan and Ben Bernanke 2005 assessment which concluded, the occurrence of a real estate bubble developing was impossible due to the Efficient Market Hypothesis, before reversing course subsequent their assertion in 2005 (Belke \& Wiedmann, 2005; Starr,2012). The result of the current study provided additional evidence supporting Eddison Walters Risk Expectation Theory of The Global Financial Crisis of 2007 and 2008. The result from data analysis also confirmed the need for the adaptation of Eddison Walters Modern Economic Analysis Theory. As a result of the findings in the current study, the researcher concluded the development of a real estate bubble is impossible where there exists real estate price transparency, as is the case in most developed and developing countries. The researcher presented Walters Real Estate Bubble Impossibility Price Transparency Theory based on the findings. False information of a real estate bubble and predictions of a real estate crash disseminated through the mainstream media and social media can be a destructive force with a disastrous effect on the economy around the world. The failure by the media to hold themselves and policymakers to a higher standard resulted in the Global Financial Crisis of 2007 and 2008. The result of the failure by the media was a worldwide economic crisis and the Great Recession that followed the Global Financial Crisis of 2007 and 2008. Lessons learned from the Global Financial Crisis of 2007 and 2008 can assist in preventing another economic crisis in the future.

Keywords: global financial crisis of 2007 and 2008, Walters real estate bubble impossibility price transparency theory, Walters and Djokic quantitative analysis factor distortion theory, Eddison Walters modern economic analysis theory, Eddison Walters risk expectation theory of the global financial crisis of 2007 and 2008, real estate bubble, advancement in Technology

\section{Introduction}

Based on the findings of the current study, policymakers must take a hard look at the media and themselves, because the world can no longer blame the subprime mortgage industry for causing the Global Financial Crisis of 2007 and 2008. The public must demand answers from the media and policymakers explaining how an economic crisis that could have been avoided resulted in the collapse of the global economy.

The lack of evidence in the literature supporting the theory of a financial bubble and the theory of a real estate bubble called for further investigation of factors leading to the Global Financial Crisis of 2007 and 2008. Evidence presented from data analysis in Walters (2018) suggested no financial bubble existed in developed or developing countries around the world, preceding the Global Financial Crisis of 2007 and 2008. Based on data analysis in Walters (2018) the evidence also suggested, the lasting effect of economic policies in response to the Global Financial Crisis of 2007 and 2008 for both developed and developing countries around the world, had no significant impact on the financial sector but pointed to a lack of economic growth. The findings raised significant questions about the existence of a real estate bubble in both developed and developing countries. Evidence from data analysis presented in Walters and Djokic (2019) suggested the existence of a real estate bubble in the United States real estate market preceding the Global Financial Crisis of 2007 and 2008 was a false conclusion. Data analysis in Walters (2019) resulted in, 0.989 Adjusted R-square, 194.041 Mean Dependent Variable, 5.908 Square Error of Regression, and 488.726 Sum-of- Square Residual for correlation between the independent variable representing advancement in technology, and the dependent variable representing home purchase price in the United States preceding the Global Financial Crisis of 2007 and 2008.

The current study expanded the investigation of the growth in home prices to fifteen developed countries around the world. Data suggested the existence of a significant near-perfect correlation in many cases, between the dependent variable representing growth in home price and the independent variable representing advancement in technology based on data analyzed from fifteen developed countries that were collected from 1990 to 2006. Data from the Organization for Economic Cooperation and Development (OECD) database which included, Canada, United Kingdom, Denmark, Finland, France, Italy, New Zealand, Sweden, Netherlands, Australia, Ireland, Belgium, Norway, Spain, and Portugal, preceding the Global Financial Crisis of 2007 and 2008 was analyzed in 
the current study.

The researcher in the current study concluded the existence of significant evidence suggesting advancement in technology was responsible for the rapid increase in home prices around the world preceding the Global Financial Crisis of 2007 and 2008. The result of the current study provided further confirmation of Eddison Walters Risk Expectation Theory of The Global Financial Crisis of 2007 and 2008, and the need for the adaptation of Eddison Walters Modern Economic Analysis Theory.

\section{Background of Study}

The motivation for the current study resulted from an investigation into the lack of evidence supporting the existence of a real estate bubble preceding the Global Financial Crisis of 2007 and 2008 in the literature, despite widespread acceptance of the theory of a real estate bubble preceding the financial crisis by researchers around the world. Eddison Walters Risk Expectation Theory of The Global Financial Crisis of 2007 and 2008 presented an alternative explanation of the true nature of the Global Financial Crisis of 2007 and 2008. The explanation ruled out the existence of a real estate bubble preceding the Global Financial Crisis of 2007 and 2008 . The theory explained the increase in home purchase price resulting from the rapid adaptation of technology in both the mortgage industry and the real estate industry from 1995 to 1999 . The theory pointed to false information from the media as a significant factor causing the financial crisis. An abundance of media coverage of the false theory of a real estate bubble, which was widely accepted without evidence supporting the claim, along with predictions of a real estate market crash, significantly increased risk expectation levels in the financial market. Evidence suggested an irrational reaction by the financial market resulting from fairs that mortgage-backed securities were worthless. Significant risk expectation in the financial market triggered the events leading to the Global Financial Crisis of 2007 and 2008. The findings of several studies by the current researcher assisted in the development of Eddison Walters Modern Economic Analysis Theory. The goal of the theory is to prevent future errors, such as the error falsely concluding the existence of a real estate bubble leading to the Global Financial Crisis.

\section{Statement of the Problem}

Evidence in previous studies by the current researcher suggested, no real estate bubble existed in the United States real estate market preceding the Global Financial Crisis of 2007 and 2008. The evidence also suggested technology was responsible for the increased demand that led to home purchase price increase. The false conclusion of the existence of a real estate bubble in many countries around the world, continue to be an area of significant concern by the current researcher today. As a result of the problem, the researcher conducted the current study that analyzed data in the real estate market of fifteen developed countries around the world, expanding the research on the United States real estate market in previous studies. Gaining an understanding of the nature of the growth of home purchase prices in the real estate market of fifteen additional developed countries, during the same period of previous studies, is critical research that will contribute to the literature. The study will significantly contribute to the understanding of the impact of advancement in technology on real estate markets around the world. The study will also significantly contribute to the understanding of the Global Financial Crisis of 2007 and 2008 and the existence of real estate bubbles. The information gained from the study can help avoid another financial crisis in the future.

\section{Purpose of the Study}

The current study focused on gaining an understanding of the impact of technology on real estate markets of developed countries around the world. The goal of the current study was to gain an understanding of the true nature of home purchase price increase around the world, to determine the likely existence of real estate bubbles in developed countries around the world during the period preceding the Global Financial Crisis of 2007 and 2008. A focus of the current study was also to settle questions associated with the possibility of the occurrence of widespread real estate bubbles in countries around the world. 


\section{Research Questions}

1. Did the data suggest the existence of a real estate bubble in developed countries around the world preceding the Global Financial Crisis of 2007 and 2008?

2. Did the adaptation of technology in the mortgage industry and real estate industry in developed countries around the world lead to a significant increase in home purchase price preceding the Global Financial Crisis of 2007 and 2008 ?

\section{Hypothesis}

Ho1: The evidence from data analysis suggested, a real estate bubble did not exist in developed countries preceding the Global Financial Crisis of 2007 and 2008.

Ha1: The evidence from data analysis suggested, a real estate bubble did exist in developed countries preceding the Global Financial Crisis of 2007 and 2008.

Ho2: The evidence from data analysis suggested, technology did not lead to a significant increase in home purchase price in developed countries preceding the Global Financial Crisis of 2007 and 2008.

Ha2: The evidence from data analysis suggested, technology did lead to a significant increase in home purchase price in developed countries preceding the Global Financial Crisis of 2007 and 2008.

\section{Nature of Study and Scope}

The current research was a quantitative study using secondary data. Mobile cellular subscriptions (per 100 people) in the United States from the World Bank Database, representing advancement in technology, and OECD House Price Index Database, representing growth in home purchase price was analyzed from 1990 to 2006 to gain an understanding of the correlation between the variables that were analyzed preceding the Global Financial Crisis of 2007 and 2008.

\section{Limitations}

Data analysis in the current study focused on explaining the correlation between the independent variable representing advancement in technology and the dependent variable representing growth in home purchase price of developed countries around the world preceding the Global Financial Crisis of 2007 and 2008. Conclusions were drawn on the existence of a real estate bubble in developed countries around the world preceding the Global Financial Crisis of 2007 and 2008, based on data analysis.

\section{Literature Review}

Several questions were raised by the current researcher, resulting from an investigation into the Global Financial Crisis of 2007 and 2008 in Walters (2018), which called for further investigation. The researcher in the current study developed the Eddison Walters Risk expectation Theory of The Global Financial Crisis of 2007 and 2008 as an alternative to the account of the Global Financial Crisis of 2007 and 2008 found widely throughout the literature. The theory was developed based on the result of data analysis in Walters (2018). The result of evidence from data analysis in the study found a lack of evidence supporting the existence of a financial bubble in the United States preceding the Global Financial Crisis of 2007 and 2008. The result of Walters (2018) called into question the entire account of the Global Financial Crisis of 2007 and 2008 in the literature, prompting further investigation by the current researcher.

Additional studies conducted in Walters and Djokic (2019); and Walters (2019) continued the development of Eddison Walters Risk Expectation Theory of The Global Financial Crisis of 2007 and 2008. Based on data 
analysis in Walters and Djokic (2019), the researchers concluded, the existence of a real estate bubble preceding the Global Financial Crisis of 2007 and 2008 was a false conclusion. Data analysis in Walters (2019) resulted in an Adjusted R-squared of 0.989 for correlation between the independent variable representing advancement in technology, and the dependent variable representing home purchase price. The result of data analysis provided overwhelming evidence; rapid growth in home purchase price in the United States between 1990 and 2006 was the result of the adaptation of technology by the real estate and the mortgage industries. Subprime mortgages and low-interest rates were ruled out as significant factors contributing to the cause of the Global Financial Crisis of 2007 and 2008 in both studies (Walters \& Djokic, 2019; Walters, 2019). The studies confirmed, Eddison Walters Risk Expectation Theory of the Global Financial Crisis of 2007 and 2008 presented an accurate account for the cause of the Global Financial Crisis of 2007 and 2008. The study also confirmed the need to update the literature to accurately reflect the true nature of the Global Financial Crisis of 2007 and 2008.

Walters (2020B) presented further evidence supporting the Eddison Walters Risk Expectation Theory of The Global Financial Crisis of 2007 and 2008. Walters (2020B) highlighted the rapid adaptation of technology between 1995 and 1999 by the real estate industry discussed in Muhanna, (2000) and by the mortgage industry discussed in Straka (2000), leading to an exponential increase in the number of qualified homebuyers. The result of the significant increase in qualified homebuyers caused a significant increase in the demand for homes (Muhanna, 2000; Straka, 2000). The increase in demand led to a rapid increase in home prices (Walters, 2020B).

Other key factors leading to the Global Financial Crisis of 2007 and 2008 highlighted in Walters 2020B, were the sensationalized media coverage of false claims of a real estate bubble by economists and predictions of a real estate crash, with no evidence presented supporting the false claims. Data analysis in Walters (2020B) presented evidence of record-low mortgage delinquencies during four quarters of 2006 preceding the start of the financial crisis, at the same time economists predicted doom and gloom for the United States housing market.

Walters (2020B) highlighted critical economic policy failures by the U.S. Administration leading to further economic deterioration resulting from the failure to restart mortgage lending. Changes to the Troubled Asset Relief Program (TARP) from the inception of the program were critical errors by U.S. policymakers highlighted in the study (Walters 2020B). The economic policy failures by the U.S. Administration resulted in an acceleration of mortgage foreclosures and almost a complete shutdown in the United States construction industry due to the lack of mortgage lending. The shutdown occurred just as the housing industry in the United States was experiencing a significant increase in demand. The significant increase in demand was due to a significant increase in the number of qualified homebuyers, resulting from the adaptation of online listings, online mortgage applications, and automated mortgage underwriting (Walters, 2020B). The adaptation of Dodd-Frank legislation one year and a half subsequent the changes to TARP, further restricted mortgage lending, at a time when mortgage lending was the most critical challenge facing the United States housing sector. The adaptation of Dodd-Frank legislation was another catastrophic error by U.S. policymakers highlighted in Walters (2020B).

Hyatt (2020) conducted research analyzing data from sixty FDIC publicly traded banks in the United States. The study analyzed data between 2004 to 2013, including several years preceding the Global Financial Crisis of 2007 and 2008, and several years after the financial crisis. The study analyzed data from a sample of thirty banks that received TARP assistance, and thirty banks that did not receive TARP assistance. The findings of data analysis revealed no significant difference between the debt-to-equity ratio for banks receiving TARP assistance and banks that did not receive TARP assistance. As a result of data analysis, the researcher concluded TARP policy implementation by the U.S. policymakers was highly ineffective (Hyatt, 2020).

Walters Modern Economic Analysis Theory was developed in Walters (2020) and confirmed in Walters (2020C). Walters (2020) presented findings from data analysis of correlation between advancement in technology and the rapid growth in home purchase price in the United States preceding the Global Financial Crisis of 2007 and 2008, making the case for the development of Eddison Walters Modern Economic Analysis Theory. Walters (2020C) analyzed data resulting in 0.996 Adjusted R-square, 1512.683 Mean Dependent Variable, 36.399 Square Error of Regression, and 18548.89 Sum-of-Square Residual, 0.000000 F-statistic for correlation between the independent variable representing advancement in technology and the dependent variable representing the increase in consumer debt in the United States preceding the Global Financial Crisis of 2007 and 2008. The researcher concluded advancement in technology was responsible for the rapid growth in consumer debt preceding the 
Global Financial Crisis of 2007 and 2008.

Eddison Walters Modern Economic Analysis Theory called for the consideration of advancement in technology as a factor when analyzing economic data for an extended period. The goal of the theory is to avoid errors from data distortion due to changes from technology (Walters, 2020; Walters, 2020C).

Data distortion from analysis that failed to consider the impact of technology on data was a critical error leading to the false conclusion of a real estate bubble. The error was determined to be a major factor leading to the Global Financial Crisis of 2007 and 2008 (Walters, 2020; Walters, 2020B; Walters, 2020C).

The sharing of information was the main function in the development of the firm (Kahai, Sara \& Kahai, 2011). The firm is the building block of the economy. Understanding the impact of technology that significantly changes the way information is shared is a critical element of analyzing data over extended periods (Walters, 2020; Walters 2020C). Walters (2020C) presented evidence from data analysis, that revealed the growth in consumer debt preceding the Global Financial Crisis of 2007 and 2008 was the result of advancement in technology. The study further confirmed the need to adapt Eddison Walters Modern Economic Analysis Theory when analyzing data over an extended period Walters (2020C).

Agarwal and Bayus (2002) discussed the effect of product innovation on market demand. The literature suggested the result of innovation is a significant increase in demand that shifts the demand curve (Agarwal \& Bayus. 2002). In the case of the real estate industry and mortgage lending industry for developed countries, the industries experienced a shift in the demand curve from the significant increase in demand from advancement in technology innovations. The move to online listings and online mortgage applications, along with automated underwriting resulting from technology innovations, significantly altered both industries. The current study noted, changes were critical factors resulting in significant home purchase price increase for developed countries.

Literature noted the critical nature of real estate market transparency, in developing real estate market stability. Chen and Hobbs (2003) conducted research that focused on measuring and explaining the global real estate market risk. The study noted increased market transparency resulted in greater real estate price certainty. The study noted market transparency was a critical factor in the assessment of real estate market risk (Chen \& Hobbs, 2003). Gholipour, Tajaddini, and Pham, (2020) considered the mortgage default rate based on the level of real estate price transparency for a sample of 46 countries between 2006 and 2016. Data analysis found a significant negative relationship between real estate market transparency and mortgage default rate (Gholipour et. $\mathrm{Al}, 2020)$. In highly transparent real estate markets, real estate price distortion is very unlikely to occur due to the transparency of real estate prices.

The literature review highlighted key elements critical to understanding the true nature of the Global Financial Crisis of 2007 and 2008 and the worldwide economic crisis that lasted for an extended period after 2008. Recent studies raised significant questions regarding the accuracy of the cause of the Global Financial Crisis of 2007 and 2008 in the literature, as the investigation focused on uncovering the truth about the financial crisis. The understanding of the effectiveness of TARP, the effect of innovation on demand, and the level of real estate price transparency that exist in developed countries are critical to understanding the true nature of the Global Financial Crisis of 2007 and 2008 and the worldwide economic crisis that lasted for several years following.

\section{Methodology}

The researcher discussed the methodology, identified the population and sample for the research. Sampling procedures, data analysis plan of action, threats to validity, and ethical procedures were also included in the methodology section. The researcher concluded with a summary.

\section{Research Questions}

1. Did the data suggest the existence of a real estate bubble in developed countries around the world preceding the Global Financial Crisis of 2007 and 2008?

2. Did the adaptation of technology in the mortgage industry and real estate industry in developed countries 
around the world lead to a significant increase in home purchase price preceding the Global Financial Crisis of 2007 and 2008 ?

\section{Hypothesis}

Ho1: The evidence from data analysis suggested, a real estate bubble did not exist in developed countries preceding the Global Financial Crisis of 2007 and 2008.

Ha1: The evidence from data analysis suggested, a real estate bubble did exist in developed countries preceding the Global Financial Crisis of 2007 and 2008.

Ho2: The evidence from data analysis suggested, technology did not lead to a significant increase in home purchase price in developed countries preceding the Global Financial Crisis of 2007 and 2008.

Ha2: The evidence from data analysis suggested, technology did lead to a significant increase in home purchase price in developed countries preceding the Global Financial Crisis of 2007 and 2008.

\section{Population}

Cellular phone subscription data from the United States was collected. House Price Index data was collected from the developed countries including, Canada, the United Kingdom, Denmark, Finland, France, Italy, New Zealand, Sweden, Netherlands, Australia, Ireland, Belgium, Norway, Spain, and Portugal.

\section{Sampling and Sampling Procedures}

Two variables were analyzed in the study. Cellular phone subscription data per one hundred in the United States collected from the World Bank Database was analyzed in the study. House Price Index collected from the OECD House Price Index Database on fifteen developed countries around the world was also analyzed in the study. Secondary data from the databases were collected from 1990 to 2006 for the study.

\section{Threats to Validity}

The validity of the data was established in the literature. The World Bank Database and the OECD House Price Index Database were established as reliable sources for secondary data in the literature. Cellular phone subscription per 100 in the United States was used as the measurement of advancement in technology to maintain a similar standard for comparing the results and drawing conclusions from the previous measurement of advancement in technology used by the researcher. Advancement in technology has been deployed at a similar rate across developing countries, therefore the researcher anticipated no bias in the data analysis from using the standard established by maintaining advancement in technology across the fifteen developed countries in the study and the United States. Data analyzed in the study was collected preceding 2007 to avoid the data being significantly skewed from government intervention policies and the turmoil in the financial market. The researcher collected data preceding 2007 as was the case in previous research that established the Eddison Walters Risk Expectation Theory and Eddison Walters Modern Economic Analysis Theory.

\section{Ethical Procedures}

Secondary data from the OECD House Price Index Database and the World Bank Database were existing databases, therefore no human subjects were involved in the research. 


\section{Results and Discussion}

\section{Data Analysis Results}

Table 1. Developed countries correlation between the dependent variable Growth in Home and the independent variable Advancement in Technology 1990 to 2006 Purchase Price

\begin{tabular}{|l|l|l|l|l|}
\hline CANADA & R-squared & Adjusted R-squared & SE. of regression & Sum squared resid \\
\hline Log likelihood & 0.969617 & 0.967592 & 1.54058 & 35.60082 \\
\hline-30.40477 & Mean dependent var & S.D. dependent var & F-statistic & Prob(F-statistic) \\
\hline UNITED KINGDOM & 42.46404 & 8.557719 & 478.7048 & 0 \\
\hline R-squared & Adjusted R-squared & S.E. of regression & Sum squared resid \\
\hline-39.02274 & 0.984622 & 0.983596 & 2.557674 & 98.12541 \\
\hline DENMLikelihood & Mean dependent var & S.D. dependent var & F-statistic & Prob(F-statistic) \\
\hline Log likelihood & 44.84753 & 19.9698 & 960.3879 & 0 \\
\hline-50.79536 & & & & Sum squared resid \\
\hline & R-squared & Adjusted R-squared & S.E. of regression & \\
\hline & 0.941057 & 0.937127 & 5.112075 & 391.9996 \\
\hline & Mean dependent var & S.D. dependent var & F-statistic & Prob(F-statistic) \\
\hline & 52.05692 & 20.38763 & 239.4833 & 0 \\
\hline
\end{tabular}

The findings nonlinear correlation analysis between the dependent variable, Growth in Home Purchase Price and the independent variable, Advancement in Technology from 1990 to 2006 for the country of Canada in Findings Number 1 resulted in, 0.968 Adjusted R-square, 42.464 Mean Dependent Variable, 1.540 Square Error of Regression, 35.601 Sum-of-Square Residual, and 478.705 F-statistic, 0.000000 Probability (F-statistic). The findings nonlinear regression analysis in Findings Number 1 resulted in a significant correlation between the growth in the independent variable of mobile cellular subscriptions (per 100 people) data, and the growth pattern of the dependent variable of home purchase price for the country of Canada preceding the Global Financial Crisis of 2007 and 2008. Correlation of variables in the case of Canada resulted in a near-perfect correlation between the variables, which is very significant therefore the researcher concluded, no real estate bubble existed in Canada real estate market preceding the Global Financial Crisis of 2007 and 2008.

The findings nonlinear correlation analysis between the dependent variable, Growth in Home Purchase Price and the independent variable, Advancement in Technology from 1990 to 2006 for the country of the United Kingdom in Findings Number 2 resulted in, 0.984 Adjusted R-square, 44.848 Mean Dependent Variable, 2.558 Square Error of Regression, 98.125 Sum-of-Square Residual, 906.388 F-statistic, 0.000000 Probability (F-statistic). The findings nonlinear regression analysis in Findings Number 2 resulted in a significant correlation between the growth in the independent variable of mobile cellular subscriptions (per 100 people) data, and the growth pattern of the dependent variable of home purchase price for the country of United Kingdom preceding the Global Financial Crisis of 2007 and 2008. Correlation of variables in the case of the United Kingdom resulted in a near-perfect correlation between the variables, which is very significant therefore the researched concluded no real estate bubble existed in the United Kingdom real estate market preceding the Global Financial Crisis of 2007 and 2008.

The findings nonlinear regression analysis in Findings Number 3 resulted in a significant correlation between the growth in the independent variable of mobile cellular subscriptions (per 100 people) data, and the growth pattern of the dependent variable of home purchase price for the country of Denmark preceding the Global Financial 
Crisis of 2007 and 2008. Correlation of variables in the case of Denmark resulted in a near-perfect correlation between the variables, which is very significant therefore the researched concluded no real estate bubble existed in Denmark real estate market preceding the Global Financial Crisis of 2007 and 2008.

The findings nonlinear correlation analysis between the dependent variable, Growth in Home Purchase Price and the independent variable, Advancement in Technology from 1990 to 2006 for the country of Denmark in Findings Number 3 resulted in, 0.937 Adjusted R-square, 52.057 Mean Dependent Variable, 5.112 Square Error of Regression, 239.483Sum-of-Square Residual, and 165.068 F-statistic. 0.000000 Probability (F-statistic). 
Table 2. Developed countries correlation between the dependent variable Growth in Home and the independent variable Advancement in Technology 1990 to 2006 Purchase Price

\begin{tabular}{|l|l|l|l|l|}
\hline FINLAND & R-squared & Adjusted R-squared & S.E. of regression & Sum squared resid \\
\hline Log likelihood & 0.858039 & 0.848575 & 5.029483 & 379.4355 \\
\hline-50.51846 & Mean dependent var & S.D. dependent var & F-statistic & Prob(F-statistic) \\
\hline FRANCE & 55.37701 & 12.92481 & 90.66276 & 0 \\
\hline Log likelihood & & & & \\
\hline-44.68591 & R-squared & Adjusted R-squared & S.E. of regression & Sum squared resid \\
\hline ITALY & 0.957166 & 0.954311 & 3.568787 & 191.0436 \\
\hline Mean dependent var & S.D. dependent var & F-statistic & Prob(F-statistic) \\
\hline Log likelihood & 53.65196 & 16.696 & 335.19 & 0 \\
\hline-46.34501 & & & & Sum squared resid \\
\hline
\end{tabular}

The findings nonlinear correlation analysis between the dependent variable, Growth in Home Purchase Price and the independent variable, Advancement in Technology from 1990 to 2006 for the country of Finland in Findings Number 4 resulted in, 0.849 Adjusted R-square, 55.377 Mean Dependent Variable, 5.029 Square Error of Regression, 379.436 Sum-of-Square Residual, and 90.663 F-statistic, 0.000000 Probability (F-statistic).

The findings nonlinear regression analysis in Findings Number 4 resulted in a significant correlation between the growth in the independent variable of mobile cellular subscriptions (per 100 people) data, and the growth pattern of the dependent variable of home purchase price for the country of Finland preceding the Global Financial Crisis of 2007 and 2008. Correlation of variables in the case of Finland resulted in a very strong correlation between the variables, which is very significant therefore the researched concluded no real estate bubble existed in Finland real estate market preceding the Global Financial Crisis of 2007 and 2008.

The findings nonlinear correlation analysis between the dependent variable, Growth in Home Purchase Price and the independent variable, Advancement in Technology from 1990 to 2006 for the country of France in Findings Number 5 resulted in, 0.954 Adjusted R-square, 53.652 Mean Dependent Variable, 3.569 Square Error of Regression, 191.044 Sum-of-Square Residual, 335.190 F-statistic, 0.000000 Probability (F-statistic). The findings nonlinear regression analysis in Findings Number 5 resulted in a significant correlation between the growth in the independent variable of mobile cellular subscriptions (per 100 people) data, and the growth pattern of the dependent variable of home purchase price for the country of France preceding the Global Financial Crisis of 2007 and 2008. Correlation of variables in the case of France resulted in a very strong. correlation between the variables, which is very significant therefore the researched concluded no real estate bubble existed in France real estate market preceding the Global Financial Crisis of 2007 and 2008.

The findings nonlinear correlation analysis between the dependent variable, Growth in Home Purchase Price and the independent variable, Advancement in Technology from 1990 to 2006 for the country of Italy in Findings Number 6 resulted in, 0.953 Adjusted R-square, 74.995 Mean Dependent Variable, 3.935 Square Error of Regression, 232.221 Sum-of-Square Residual, 325.649 F-statistic, 0.000000 Probability (F-statistic). The findings nonlinear regression analysis in Findings Number 6 resulted in a significant correlation between the growth in the independent variable of mobile cellular subscriptions (per 100 people) data, and the growth pattern of the dependent variable of home purchase price for the country of Italy preceding the Global Financial Crisis 
of 2007 and 2008. Correlation of variables in the case of Italy resulted in a near-perfect correlation between the variables, which is very significant therefore the researcher concluded, no real estate bubble existed in Italy real estate market preceding the Global Financial Crisis of 2007 and 2008. 
Table 3. Developed countries correlation between the dependent variable Growth in Home and the independent variable Advancement in Technology 1990 to 2006 Purchase Price

\begin{tabular}{|l|l|l|l|l|}
\hline NEW ZEALAND & R-squared & Adjusted R-squared & S.E. of regression & Sum squared resid \\
\hline Log likelihood & 0.943053 & 0.939256 & 3.363211 & 169.6678 \\
\hline-43.6773 & Mean dependent var & S.D. dependent var & F-statistic & Prob(F-statistic) \\
\hline SWEDEN & 36.61941 & 13.64593 & 248.4015 & 0 \\
\hline Log likelihood & & & & \\
\hline-31.84265 & R-squared & Adjusted R-squared & S.E. of regression & Sum squared resid \\
\hline NETHERLANDS & 0.97673 & 0.975179 & 1.676553 & 42.16247 \\
\hline Log likelihood & Mean dependent var & S.D. dependent var & F-statistic & Prob(F-statistic) \\
\hline-64.66879 & 34.59255 & 10.64163 & 629.6167 & 0 \\
\hline & R-squared & Adjusted R-squared & S.E. of regression & Sum squared resid \\
\hline & 0.85779 & 0.848309 & 11.5616 & 2005.059 \\
\hline
\end{tabular}

The findings nonlinear correlation analysis between the dependent variable, Growth in Home Purchase Price and the independent variable, Advancement in Technology from 1990 to 2006 for the country of New Zealand in Findings Number 7 resulted in, 0.939 Adjusted R-square, 36.619 Mean Dependent Variable, 3.363 Square Error of Regression, 169.668 Sum-of-Square Residual, 248.402 F-statistic, 0.000000 Probability (F-statistic). The findings nonlinear regression analysis in Findings Number 7 resulted in a significant correlation between the growth in the independent variable of mobile cellular subscriptions (per 100 people) data, and the growth pattern of the dependent variable of home purchase price for the country of New Zealand preceding the Global Financial Crisis of 2007 and 2008. Correlation of variables in the case of New Zealand resulted in a near-perfect correlation between the variables, which is very significant therefore the researched concluded no real estate bubble existed in the New Zealand real estate market preceding the Global Financial Crisis of 2007 and 2008.

The findings nonlinear correlation analysis between the dependent variable, Growth in Home Purchase Price and the independent variable, Advancement in Technology from 1990 to 2006 for the country of Sweden in Findings Number 8 resulted in, 0.975 Adjusted R-square, 34.593 Mean Dependent Variable, 1.677 Square Error of Regression, 42.162 Sum-of-Square Residual, 629.617 F-statistic, 0.000000 Probability (F-statistic). The findings nonlinear regression analysis in Findings Number 8 resulted in a significant correlation between the growth in the independent variable of mobile cellular subscriptions (per 100 people) data, and the growth pattern of the dependent variable of home purchase price for the country of Sweden preceding the Global Financial Crisis of 2007 and 2008. Correlation of variables in the case of Sweden resulted in a near-perfect correlation between the variables, which is very significant therefore the researcher concluded, no real estate bubble existed in Sweden real estate market preceding the Global Financial Crisis of 2007 and 2008.

The findings nonlinear correlation analysis between the dependent variable, Growth in Home Purchase Price and the independent variable, Advancement in Technology from 1990 to 2006 for the country of Netherlands in Findings Number 9 resulted in, 0.848 Adjusted R-square, 65.568 Mean Dependent Variable, 11.562 Square Error of Regression, 2005.059 Sum-of-Square Residual, 90.478 F-statistic, 0.000000 Probability (F-statistic). The findings nonlinear regression analysis in Findings Number 9 resulted in a significant correlation between the growth in the independent variable of mobile cellular subscriptions (per 100 people) data, and the growth pattern of the dependent variable of home purchase price for the country of Netherlands preceding the Global Financial Crisis of 2007 and 2008. Correlation of variables in the case of the Netherlands resulted in a very strong correlation between the variables, which is very significant therefore the researched concluded no real estate bubble existed in the Netherlands real estate market preceding the Global Financial Crisis of 2007 and 2008. 
Table 4. Developed countries correlation between the dependent variable Growth in Home and the independent variable Advancement in Technology 1990 to 2006 Purchase Price

\begin{tabular}{|c|c|c|c|c|}
\hline AUSTRALIA & R-squared & Adjusted R-squared & SE. of regression & Sum squared resid \\
\hline & 0.964802 & 0.962456 & 2.579777 & 99.82877 \\
\hline Log likelihood & Mean dependent var & S.D. dependent var & F-statistic & Prob(F-statis tic) \\
\hline-39.16902 & 35.25528 & 13.31406 & 411.1638 & 0 \\
\hline \multirow[t]{2}{*}{ IRELAND } & R-squared & Adjusted R-squared & SE. of regression & Sum squared resid \\
\hline & 0.969192 & 0.967138 & 7.383568 & 817.7562 \\
\hline Log likelihood & Mean dependent var & S.D. dependent var & F-statis tic & Prob(F-statistic) \\
\hline-57.04544 & 68.87448 & 40.73046 & 471.8847 & 0 \\
\hline \multirow[t]{2}{*}{ BELGIUM } & R-squared & Adjusted R-squared & SE. of regres sion & Sum squared resid \\
\hline & 0.964713 & 0.96236 & 2.77902 & 115.8443 \\
\hline Log likelihood & Mean dependent var & S.D. dependent var & F-statis tic & Prob(F-statis tic) \\
\hline-40.43374 & 48.25772 & 14.32411 & 410.0815 & 0 \\
\hline
\end{tabular}

The findings nonlinear correlation analysis between the dependent variable, Growth in Home Purchase Price and the independent variable, Advancement in Technology from 1990 to 2006 for the country of Australia in Findings Number 10 resulted in, 0.965 Adjusted R-square, 35.255 Mean Dependent Variable, 2.580 Square Error of Regression, 99.829 Sum-of-Square Residual, 411.164 F-statistic, 0.000000 Probability (F-statistic). The findings nonlinear regression analysis in Findings Number 10 resulted in a significant correlation between the growth in the independent variable of mobile cellular subscriptions (per 100 people) data, and the growth pattern of the dependent variable of home purchase price for the country of Australia preceding the Global Financial Crisis of 2007 and 2008. Correlation of variables in the case of Australia resulted in a near-perfect correlation between the variables, which is very significant therefore the researcher concluded, no real estate bubble existed in the Australia real estate market preceding the Global Financial Crisis of 2007 and 2008.

The findings nonlinear correlation analysis between the dependent variable, Growth in Home Purchase Price and the independent variable, Advancement in Technology from 1990 to 2006 for the country of Ireland in Findings Number 11 resulted in, 0.967 Adjusted R-square, 68.87448 Mean Dependent Variable, 7.384 Square Error of Regression, 817.756 Sum-of-Square Residual, 471.885 F-statistic, 0.000000 Probability (F-statistic). The findings nonlinear regression analysis in Findings Number 11 resulted in a significant correlation between the growth in the independent variable of mobile cellular subscriptions (per 100 people) data, and the growth pattern of the dependent variable of home purchase price for the country of Ireland preceding the Global Financial Crisis of 2007 and 2008. Correlation of variables in the case of Ireland resulted in a near-perfect correlation between the variables, which is very significant therefore the researcher concluded, no real estate bubble existed in Ireland real estate market preceding the Global Financial Crisis of 2007 and 2008.

The findings nonlinear correlation analysis between the dependent variable, Growth in Home Purchase Price and the independent variable, Advancement in Technology from 1990 to 2006 for the country of Belgium in Findings Number 12 resulted in, 0.962 Adjusted R-square, 48.258 Mean Dependent Variable, 2.779 Square Error of Regression, 115.844 Sum-of-Square Residual, 410.082 F-statistic, 0.000000 Probability (F-statistic). The findings nonlinear regression analysis in Findings Number 12 resulted in a significant correlation between the growth in the independent variable of mobile cellular subscriptions (per 100 people) data, and the growth pattern of the dependent variable of home purchase price for the country of Belgium preceding the Global Financial Crisis of 2007 and 2008. Correlation of variables in the case of Belgium resulted in a near-perfect correlation between the variables, which is very significant therefore the researcher concluded, no real estate bubble existed in Belgium real estate market preceding the Global Financial Crisis of 2007 and 2008. 
Table 5. Developed countries correlation between the dependent variable Growth in Home and the independent variable Advancement in Technology 1990 to 2006 Purchase Price

\begin{tabular}{|c|c|c|c|c|}
\hline NORWAY & R-squared & Adjusted R-squared & S.E. of r egression & Sum squared resid \\
\hline & 0.932317 & 0.927805 & 3.748944 & 210.8188 \\
\hline Log likelihood & Mean dependent var & S.D. dependent var & F-statistic & Prob(F-statistic) \\
\hline-45.52313 & 34.37934 & 13.95263 & 206.6227 & 0 \\
\hline \multirow[t]{2}{*}{ SPAIN } & R-squared & Adjusted R-squared & S.E. of regression & Sum squared resid \\
\hline & 0.985525 & 0.98456 & 3.720365 & 207.6168 \\
\hline Log likelihood & Mean dependent var & S.D. dependent var & F-statistic & Prob(F-statistic) \\
\hline-45.39304 & 64.00572 & 29.94061 & 1021.263 & 0 \\
\hline \multirow[t]{2}{*}{ PORT UGAL } & R-squared & Adjusted R-squared & S.E. of regression & Sum squared resid \\
\hline & 0.746631 & 0.72974 & 9.251468 & 1283.845 \\
\hline Log likelihood & Mean dependent var & S.D. dependent var & F-statistic & Prob(F-statistic) \\
\hline-60.87937 & 89.03536 & 17.79589 & 44.20224 & 0.000008 \\
\hline
\end{tabular}

The findings nonlinear correlation analysis between the dependent variable, Growth in Home Purchase Price and the independent variable, Advancement in Technology from 1990 to 2006 between the dependent variable, Growth in Home Purchase Price and the independent variable, Advancement in Technology from 1990 to 2006 for the country of Norway in Findings Number 13 resulted in, 0.928 Adjusted R-square, 34.379 Mean Dependent Variable, 34.379 Square Error of Regression, 210.819 Sum-of-Square Residual, 206.623 F-statistic, 0.000000 Probability (F-statistic). The findings nonlinear regression analysis in Findings Number 13 resulted in a significant correlation between the growth in the independent variable of mobile cellular subscriptions (per 100 people) data and the growth pattern of the dependent variable of home purchase price for the country of Norway preceding the Global Financial Crisis of 2007 and 2008. Correlation of variables in the case of Norway resulted in a near-perfect correlation between the variables, which is very significant therefore the researcher concluded, no real estate bubble existed in Norway real estate market preceding the Global Financial Crisis of 2007 and 2008.

The findings nonlinear correlation analysis between the dependent variable, Growth in Home Purchase Price and the independent variable, Advancement in Technology from 1990 to 2006 for the country of Spain in Findings Number 14 resulted in, 0.985 Adjusted R-square, 64.006 Mean Dependent Variable, 3.720 Square Error of Regression, 207.617 Sum-of-Square Residual, 1021.263 F-statistic, 0.000000 Probability (F-statistic). The findings nonlinear regression analysis in Findings Number 14 resulted in a significant correlation between the growth in the independent variable of mobile cellular subscriptions (per 100 people) data, and the growth pattern of the dependent variable of home purchase price for the country of Spain preceding the Global Financial Crisis of 2007 and 2008. Correlation of variables in the case of Spain resulted in a near-perfect correlation between the variables, which is very significant therefore the researcher concluded, no real estate bubble existed in Spain real estate market preceding the Global Financial Crisis of 2007 and 2008.

The findings nonlinear correlation analysis between the dependent variable, Growth in Home Purchase Price and the independent variable, Advancement in Technology from 1990 to 2006 for the country of Portugal in Findings Number 15 resulted in, 0.747 Adjusted R-square, 89.035 Mean Dependent Variable, 9.251 Square Error of Regression, 1283.845 Sum-of-Square Residual, 44.202 F-statistic, 0.000008 Probability (F-statistic). The findings nonlinear regression analysis in Findings Number 15 resulted in a significant correlation between the growth in the independent variable of mobile cellular subscriptions (per 100 people) data, and the growth pattern of the dependent variable of home purchase price for the country of Portugal preceding the Global Financial Crisis of 2007 and 2008. Correlation of variables in the case of Portugal resulted in a strong correlation between the variables, which is very significant therefore the researched concluded no real estate bubble existed in Portugal real estate market preceding the Global Financial Crisis of 2007 and 2008. 


\section{Hypothesis Testing}

Ho1: The evidence from data analysis suggested, a real estate bubble did not exist in developed countries preceding the Global Financial Crisis of 2007 and 2008. The researcher rejected H1o.

Ha1: The evidence from data analysis suggested, a real estate bubble did exist in developed countries preceding the Global Financial Crisis of 2007 and 2008. The researcher failed to reject H1a.

Ho2: The evidence from data analysis suggested, technology did not lead to a significant increase in home purchase price in developed countries preceding the Global Financial Crisis of 2007 and 2008. The researcher rejected $\mathrm{Ho2}$.

Ha2: The evidence from data analysis suggested, technology did lead to a significant increase in home purchase price in developed countries preceding the Global Financial Crisis of 2007 and 2008. The researcher failed to reject $\mathrm{H} 2 \mathrm{a}$.

\section{Research Question Result}

1. The researcher found the data presented no evidence supporting the idea, the existence of a real estate bubble in developed countries around the world preceding the Global Financial Crisis of 2007 and 2008.

2. The researcher found the data presented evidence supporting the idea, the adaptation of technology in the mortgage industry and real estate industry in developed countries around lead to a significant increase in home purchase price preceding the Global Financial Crisis of 2007 and 2008

\section{Discussion}

Based on the findings of the current study, policymakers must take a hard look at the media and themselves, because the world can no longer blame the subprime mortgage industry for causing the Global Financial Crisis of 2007 and 2008. The findings of the current study will force policymakers around the world to come to terms with the truth about the media false information that started the Global Financial Crisis of 2007 and 2008. Policymakers must also come to terms with the policy failures focused on solving a real estate bubble that did not exist leading to the worldwide economic crisis. An accurate explanation for how the worldwide economic crisis resulted in the Great Recession subsequent the financial crisis must be given by policymakers. The public must demand answers from both the media and policymakers that explain why an economic crisis that could have been avoided cause the entire global economy to collapse. Answering the difficult questions about the truth of the Global Financial Crisis could be the key to ensure an economic crisis of the same magnitude is avoided in the future.

Data analysis in the case of all fifteen developed countries in the current study suggested no real estate bubble existed preceding the Global Financial Crisis of 2007 and 2008. Based on data analysis evidence, the rapid increase in home purchase price was the result of advancement in technology for all fifteen developed countries. The result of data analysis in the current study confirmed the accuracy of former Federal Reserve Board Chairmen, Alan Greenspan and Ben Bernanke 2005 assessment which concluded the impossibility of occurrence of a real estate bubble development due to the Efficient Market Hypothesis, before reversing course subsequent their assertion in 2005 (Belke \& Wiedmann, 2005; Starr,2012). The findings of the study serve as additional confirmation of Eddison Walters Risk Expectation Theory of The Global Financial Crisis of 2007 and 2008, and the need to adapt Eddison Walters Modern Economic Analysis Theory for analyzing economic data over an extended period.

The lack of consideration of the impact of advancement in technology on the transformation of both the real estate and mortgage industries resulted in economic policy failures around the world. Policymakers accepted the theory of a real estate bubble without investigating for evidence supporting the claims. The failure by the media to hold policymakers accountable by requesting evidence supporting claims of a real estate bubble and predictions of a real estate market crash is very troubling. Equally troubling is the idea the motivation of the media may have been a favorable political narrative to influence the 2008 election. Had the media held policymakers to a higher standard, policymakers would have been forced to produce evidence. Accountability by 
the media could have resulted in an investigation to uncover the true nature of the financial crisis, leading to proper corrective actions, avoiding such a significant economic crisis. The media failure in their responsibility to hold policymakers accountable significantly contributed to the Global Financial Crisis of 2007 and 2008.

The result of data analysis suggested, growth in home purchase price for developed countries around the world preceding the Global Financial Crisis of 2007 and 2008 resulted from increased demand for homes, due to changes in the real estate and mortgage industries resulting from advancement in technology. The transformation of the real estate industry to online real estate listings and the transformation of the mortgage industry from automated underwriting and online mortgage applications shifted the demand curve in the real estate market. The shift in the demand curve resulted from an exponential number of new qualified home buyers in the market. Economist analyzing the increase in home purchase price made a significant error by analyzing all data on a demand curve that no longer existed by early 2000. The most critical error in the false conclusion of the existence of a real estate bubble was, the failure to consider the shift in the demand curve resulting from advancement in technology.

The widespread acceptance of the theory of a real estate bubble by policymakers around the world and the implementation of policies similar to TARP, which was implemented with the focus on bank bailouts, while ignoring the real problem of the lack of mortgage lending. Policymakers around the world implemented policies in response to the financial crisis in the same way TARP was implemented by U.S. policymakers. The implementation of policies with no investigation to gain an understanding of the true nature of the economic challenges was a critical error leading to a complete collapse of the worldwide economy and the Great Recession. At a time when data was abundant and at the fingertips, there was no excuse for policymakers implementing drastic measures such as the policies which were implemented in response to the financial crisis in countries around the world, based on junk science.

The Global Financial Crisis of 2007 and 2008 was a catastrophic failure of epic proportions at every level. The worldwide economic crisis dragged on for several years based on the false conclusion of a real estate bubble, significantly affecting families with lower income more than any other segment of the population around the world. The Global Financial Crisis was a massive transfer of real estate wealth away from lower and modest-income families.

The media played a significant role in causing the Global Financial Crisis of 2007 and 2008. The dissemination of false information of a real estate bubble and predictions of a real estate market crash were critical factors that set the Global Financial Crisis of 2007 and 2008 in motion. The media acceptance of the false narrative and failure to hold policymakers accountable in favor of a political narrative was a significant avocation of their responsibility to the entire world.

The role the financial market played in causing the Global Financial Crisis of 2007 and 2008 was a significant factor. The irrational reaction by the financial market based on false information from the media started the economic crisis. Once the turmoil in the financial market started, the market exhibited a herd mentality, and the entire market ran in the same direction without stopping to evaluate the true nature of the crisis. Financial regulators also failed to contain the crisis.

The result of data analysis in Hyatt (2020), provided evidence of the critical nature of errors made by U.S. policymakers that changed TARP from the original intent. The original intent of TARP was to invest in mortgage-backed securities to restart mortgage lending. Policy changes to TARP by the U.S. Administration focused on saving the banks but provided little assistance to homeowners experiencing economic hardship. As a result of the changes to TARP, policymakers used taxpayers' funding to take ownership stakes in banks, providing the liquidity for banks to continue operations with the bank-bailout. Struggling homeowners, whose taxes assisted funding the bank-bailout, got very little in return because there was no mandate for rescued banks receiving taxpayer dollars to refinance mortgages for homeowners experiencing hardship.

Failure by policymakers more focused on a political narrative than an investigation to uncover the true nature of the economic crisis was an inexcusable error. The significant error by policymakers deepened the economic crisis. The focus on bank rescue programs similar to TARP with the priority of solving the problem of a real estate bubble that did not exist failed to address the real problem which was the need to restart mortgage lending. The crisis based on false information continued for years without assessment to understand the effectiveness of 
policies that were implemented. The failure to take a critical look at the Global Financial Crisis of 2007 and 2008 to ensure the same mistakes were not made over and over, was also a critical error by policymakers around the world.

The failure by economists that did not consider the effect of technology adaptation in the real estate and mortgage industries was another key factor leading to the Global Financial Crisis of 2007 and 2008. The politicization of quantitative analysis, which should never consider personal opinions as scientific evidence when conducting economic analysis, was a significant factor leading to the Global Financial Crisis of 2007 and 2008. The abandonment of scientific analysis in favor of political analysis has created a crisis in quantitative analysis, resulting in unreliable data analysis. The failure by economists to conduct analysis based on scientific research must be addressed to avoid future errors in economic data analysis leading to another crisis.

The failure by economists to consider the impact of technology on economic data continues today. The evidence suggested the theory of a real estate bubble is a theory lacking credibility and economic foundation. The researcher in the current study therefore introduced Walters Real Estate Bubble Impossibility Price Transparency Theory. The foundation of the theory is based on the Efficient Market Hypothesis. The theory underscores the following points:

1. There may be a rear occurrence of price distortion in isolated real estate markets from time to time.

2. Price distortions in an isolated real estate market most likely may be the result of illegal activity or false information influencing the real estate market, as was the case preceding the Global Financial Crisis of 2007 and 2008.

3. Based on the existence of real estate price transparency, the likelihood of any widespread real estate bubble occurrence is not possible based on the Efficient Market Hypothesis.

The lack of evidence supporting the theory of a real estate bubble in the literature is quite troubling. The idea, there exists such a broad consensus of the existence of a real estate bubble without analyzing reliable data in support of the widely accepted theory underscores the need for the development of new theories focused on avoiding critical errors in economic analysis of the same magnitude in the future.

The result of data analysis in the current study served as additional confirmation of, Eddison Walters Risk Expectation Theory of The Global Financial Crisis of 2007 and 2008. The current study also presented additional evidence supporting the need to adapt Eddison Walters Modern Economic Analysis Theory when analyzing economic data over an extended period. The current study provided further confirmation of the accuracy of former Federal Reserve Board Chairmen, Alan Greenspan, and Ben Bernanke 2005 assessment which concluded the occurrence of a real estate bubble development was impossible due to the Efficient Market Hypothesis (Belke \& Wiedmann, 2005; Starr,2012). Both former Federal Reserve Board Chairmen reversed their conclusions subsequent to their assertions in 2005.

Walters Real Estate Bubble Impossibility Price Transparency Theory is presented in the current study. The new theory continues the development of theories needed to address potential errors such as the error discussed in the current study. Continued research and development of theory focused on the reliability and validity of economic analysis will significantly lower the risk of data distortion from the lack of consideration of the effect of advancement in technology in economic data. Continued development of theory on the subject, can assist in preventing the same mistakes, leading to another significant economic crisis in the future.

A significant problem in quantitative research is changing factors that are assumed to be constant, leading to data distortion which amounts to junk science. The politicization of quantitative analysis has exasperated the problem leading to policies that expose the global economy to significant risks. The error of changing factors that are assumed to be constant, leading to unreliable data analysis, was quite apparent by acceptance of false conclusions of a real estate bubble, and today is quite apparent in climate change policy and policies to combat COVID-19.

There are many unknowns about the world and the universe, but the area where there is no dispute is the dynamic nature of the universe. Changes in the gravitational pull as the earth rotate on the axis and around the 
sun, planetary alignment, the position of the moon, and the asymmetrical nature of the earth are all factors that result in the occurrence of events in the solar system which can be decades apart. This is due to the constant changes in the universe. Climate change policies are based on assumptions that fail to recognize the dynamic nature of the universe and pretend the universe is static in data analysis. The assumption the factors remain constant result in findings that are not grounded in scientific research.

Data analysis and developed policies aimed at reversing climate change based on false assumptions, significantly increasing risk to the global economy. Analysis of climate change fails to consider changing factors at work in the universe. A common error made by researchers analyzing climate change is another example of data distortion resulting from the lack of consideration of changing factors, which is the same error that resulted in the false conclusion of a real estate bubble preceding the Global Financial Crisis of 2007 and 2008. The commitment of significant resources away from priorities with the potential of significant efficiency gains throughout the global economy, along with the adaptation of policies that significantly decrease efficiency in favor of combating climate change is misguided. The assumption of all else being equal is a significant error and another example of false information that can have significant consequences for the global economy.

There are also significant questions regarding the reliability and validity of analysis on COVID-19 data resulting from changing factors assumed to be constant, resulting in policies based on false information. Changing factors such as the health of a population resulting from changes in the diet and other behaviors which are more or less acceptable from country to country, the difference in population density, and climate changes are all changing factor which has been assumed to be constant that can have a significant effect on the spread. The assumption changing factors are constant in the case of COVID-19 is the very same error that led to the false conclusion of a real estate bubble preceding the Global Financial Crisis of 2007 and 2008.

The researcher in the current study announces the development of Walters and Djokic Quantitative Analysis Factor Distortion Theory. The goal of the theory is to address changing factors assumed to be constant in quantitative research analysis with significant potential to distort the findings from data analysis that is currently ignored by researchers. The theory states the following:

1. It is a significant error to assume changing factors are constant in quantitative analysis.

2. The assumption of changing factor to be constant ignores a key principle of quantitative analysis on which conclusions from data analysis are based which is, "all else being equal".

3. Changing factors assumed to be constant in quantitative analysis result in significant data distortion resulting in a lack of reliability and validity of finding in quantitative research.

In the upcoming study, Walters and Djokic Quantitative Analysis Factor Distortion Theory will continue the development of steps to be taken in the literature to address changing factors assumed to be constant with the potential to cause data distortion errors in quantitative research.

\section{Areas of Future Research}

The are several areas that must be considered for future studies. Recent politicization of quantitative data analysis has ignored key factors critical to scientific research, which can significantly distort the findings from data analysis resulting in false conclusions. The reliability and validity of quantitative data analysis require researchers to account for changing factors. Changing factors that are assumed to be constant in quantitative research is a significant error. Future research aimed at addressing the reliability and validity of quantitative data analysis is required. The widespread acceptance of the theory of a real estate bubble by policymakers around the world and the implementation of policies similar to TARP, which was implemented by policymakers without investigation to gain an understanding of the true nature of the Global Financial Crisis of 2007 and 2008, is an area of research for future studies. Future research aimed at accurately reflecting the true nature of the Global Financial Crisis of 2007 and 2008 and the significant economic policy errors by policymakers around the world in response to a real estate bubble that did not exist is also needed. 


\section{Conclusion}

Based on the result of data analysis the evidence suggested, growth in home purchase price for developed countries preceding the Global Financial Crisis of 2007 and 2008, resulted from increased demand for homes. The increased demand for homes was due to the adaptation of technology in the real estate industry and the mortgage industry. The move to online listings and online mortgage loan applications, along with automated underwriting between 1995 and 1999 shifted the demand curve for homes.

There are continued claims of the existence of real estate bubbles in many countries around the world today. The claims are based on the lack of understanding of the significant impact of advancement in technology on the increased demand for homes, along with the impact of economic policies that stifled home inventory levels that was aimed at a real estate bubble that did not exist. The lack of understanding resulted in an almost complete shutdown of real estate development for several years subsequent to the Global Financial Crisis of 2007 and 2008. The shutdown occurred just as demand in housing markets around the world was entering a rapid growth stage from the significant increase in demand, which is very common following changes due to innovation in many industries.

The lasting effect of the false conclusion of a real estate bubble and the effect on economies around the world resulting from the false media narrative is very significant. The failed economic policies aimed at solving a real estate bubble that did not exist have resulted in an even greater acceleration of growth in home purchase prices. The rapid acceleration in the growth of home purchase price is due to the significant increase in demand for homes, along with inadequate levels of housing to meet demand in many countries around the world.

The combination of the increase in demand for homes and the shortage in home inventory levels have become a potential looming housing crisis for moderate-income families in many countries around the world. Due to market forces, there has been a rapid acceleration of the increase in home purchase prices resulting from a significant shortage in home inventories. Many economists in countries around the world have made the same error, falsely concluding the existence of a real estate bubble today. The shortage in home inventory has

significantly increased the cost of rental housing. The current housing situation has exposed a potential housing crisis for moderate-income families in many countries around the world. The looming housing crisis for moderate-income families priced out of the housing market is a challenge requiring immediate attention from policymakers. Failure of action by policymakers to address challenges associated with the significant increase in the cost of housing, as the world address challenges associated with Covid-19, could result in a significant worldwide homeless crisis.

The lack of understanding of the impact of technology on home purchase price was a significant error leading to the Global Financial Crisis of 2007 and 2008. The early-stage adaptation of widespread use of technology through the economy dates back about two and a half decades. The recent widespread incorporation of technology across the global economy has resulted in very few experts possessing a deeper understanding of the significant effect of advancement in technology on the economy. Significant research is needed in the area to gain a deeper understanding of the disruptive nature of advancement in technology that continues to drastically alter the sharing of information throughout the economy today.

The overwhelming evidence of correlation for the independent variable representing advancement in technology, and the dependent variable representing home purchase price uncovered evidence suggesting, advancement in technology was the most significant factor causing the significant increase in home purchase price in developed countries around the world preceding the Global Financial Crisis of 2007 and 2008. The current study concluded, there is no possibility of the existence of widespread real estate bubbles in real estate markets resulting from price transparency.

Walters Real Estate Bubble Impossibility Price Transparency Theory was presented in the current study due to overwhelming evidence which suggested, the existence of a false conclusion of a real estate bubble preceding the Global Financial Crisis of 2007 and 2008. The result of data analysis on home purchase price in fifteen developed countries around the world in the current study, in addition to data analysis on home purchase price in the United States in previous studies, resulted in the findings, no real estate bubble existed in the total of sixteen developed countries with a rapid increase in home purchase price around the world during the period preceding 
the Global Financial Crisis of 2007 and 2008 .

The development of Walters Real Estate Bubble Impossibility Price Transparency Theory was developed to end any dispute that may persist by frequent claims from economists' constant suggestions of the existence of real estate bubbles around the world today. The level of real estate price transparency existing in most countries, especially in developed countries, makes the likelihood of the existence of a real estate bubble impossible. The foundation of Walters Real Estate Bubble Impossibility Price Transparency Theory is based on the Efficient Market Hypothesis. The goal of the new theory is to end false claims of real estate bubbles that persist around the world today. The adaptation of Walters Real Estate Bubble Impossibility Price Transparency Theory will avoid the error of false information of a real estate bubble leading to an economic crisis in the future.

False information of a real estate bubble and predictions of a real estate crash disseminated through mainstream media and social media can be a destructive force with a disastrous effect on the economy around the world. The failure by the media to hold themselves and policymakers to a higher standard resulted in the Global Financial Crisis of 2007 and 2008. The challenge for policymakers is a difficult balancing act of holding the media accountable while protecting the freedom of the press.

The current study exposed an even greater challenge that must address. The challenge is to reduce the risk of the likelihood of another worldwide economic crisis. Collection of data and disproportional control information sharing by a small number of media and technology companies are a problem with significant consequences for the worldwide economy. The limited number of technology companies' dominating control over the world's economy through data collection and information sharing, give these companies greater control of the economy policymakers themselves. The sharing of information is the foundation of the development of the theory of the firm. The firm is the basic building block of the world's economy. Allowing a small group of private industry companies to continue disproportional control of information shared around the world exposes the global economy to significant risk.

The lack of competition for many in the technology sector, the control of news media organizations by technology companies and recent censorship policies, along fact check policies by individuals with no expertise on the subject matter, adopted by both mainstream media and social media companies, significantly increase the likelihood false information could lead to another worldwide economic crisis. The idea of the current study and previous studies on the Global Financial Crisis of 2007 and 2008 by the current researcher, based on evidence from data collected by government databases, can be censored because the findings of studies fall outside the narrative widely accepted throughout the current literature is very troubling. Steps must be taken to reduce the likelihood of another worldwide economic crisis resulting from false information

An area of concern highlighted by the findings of the current study and other studies by the current researcher, is the potential danger from the expanding role of private-sector technology firms in the economy, with monetary policy through cryptocurrency. Significant risk exists which is associated with diluting control of monetary policy away from central banks to technology sector companies with dominant control over the sharing of information which is the foundation of the economy. The European Debt Crisis should serve as an example of the risk associated with countries that do not have full control of a central bank and monetary policy as a tool to stabilize economies. The potential lack of full control of monetary policy by central banks in favor of allowing cryptocurrency by private sector companies in the technology industry, along with technology companies' control of the economy through the sharing of information put the global economy at significant risk.

The risk exposure to the global economy from the dissemination of false information is substantial. The risk created by consensus on climate change policies developed based on data analysis with false assumptions amounts to junk science, with significant economic risk to the global economy. Significant resources along with policies aimed at reversing climate change with very little evidence presented on the effectiveness have the potential to cripple economies, leading to an economic crisis. A significant error made in data analysis on climate change, and COVID-19 is the assumption, changing factors remain constant. The error is the same error that led to the false conclusion of a real estate bubble preceding the Global Financial Crisis of 2007 and 2008.

Lessons learned from the Global Financial Crisis of 2007 and 2008 can assist in preventing another worldwide economic crisis in the future, but swift action must be taken by policymakers to reduce the risk associated with the dissemination of false information throughout the economy. Lessons from the financial crisis should serve as 
an example of the critical nature of the need to diversify the sharing of information throughout the economy and the devastation that can result from false information. The current study has established there is a significant contribution that can be gained from dissenting ideas falling outside the consensus of the mainstream. The sharing of accurate information is such a critical factor in the economic well-being of the global economy, steps must be taken to limit risk from false information causing a future global economic crisis. 


\section{References}

Agarwal, R., \& Bayus, B. (2002). The market evolution and sales takeoff of product innovations. Management Sci., 48(8), 1024-1052. https://doi.org/10.1287/mnsc.48.8.1024.167

Belke, A., \& Wiedmann, M. (2005). Boom or bubble in the US real estate market? Inter economics, 40(5), 273-284. https://doi.org/10.1007/s10272-005-0157-0

Chen, J., \& Hobbs, P. (2003). Global Real Estate Risk Index. The Journal of Portfolio Management. Special Real Estate Issue, 66-75. https://doi.org/10.3905/jpm.2003.319908

Gholipour, H. F., Tajaddini, R., \& Pham T. (2020). Real estate market transparency and default on mortgage. Research in International Business and Finance, 53. https://doi.org/10.1016/j.ribaf.2020.101202

Hyatt, A. (2020) Investment transactions and capital structure among U.S. commercial banks: The TARP factor. ProQuest Dissertations Publishing, 2020. Retrieved from https://search.proquest.com/openview/08c4ace7db13b7c1363e7062ad61458b/1?pq-origsite=gscholar\&cbl= $18750 \&$ diss $=\mathrm{y}$

Kahai, S. K., Sara, T. S., \& Kahai, P. S. (2011). Off-Shoring and outsourcing. Journal of Applied Business Research (JABR), 27(1). https://doi.org/10.19030/jabr.v27i1.915

Muhanna, W. A. (2000). E-Commerce in the real estate brokerage industry. Journal of Real Estate Practice and Education, 3(1), 1-16. https://doi.org/10.1080/10835547.2000.12091570

OECD.org. (2020). Organisation for Economic Co-operation and Development. Retrieved from https://data.oecd.org/price/housing-prices.htm

Starr, M. A. (2012). Contributions of economists to the housing-price bubble. Journal of Economic Issues, 46(1), 143-171. https://doi.org/10.2753/JEI0021-3624460106

Straka, J. W. (2000). A shift in the mortgage landscape: The 1990's move to automated credit evaluations. Journal of Housing Research, 11(2), 207-231. Retrieved from https://pdfs.semanticscholar.or/38ce/5ff03c453f2594251dec35203b3891dcedaf.pdf

Walters, E. T. (2018). Changes in FDI inflows and economic growth and the effect on exports: The aftermath of The Global Financial Crisis of 2007 and 2008 (Order No.10976977). Retrieved from https://search.proquest.com/docview/2135243535? accountd=35796

Walters, E. T. (2019). Growth in home purchase price preceding crisis explained by technology advancement: Eddison Walters Risk Expectation Theory of The Global Financial Crisis of 2007 and 2008 confirmed. Journal of International Business and Economics, 7(2), 140-153. Published by American Research Institute for Policy Development. https://doi.org/10.15640/jibe.v7n2a15

Walters, E. T. (2020). Eddison Walters Modern Economic Analysis Theory: Building on the Eddison Walters Risk Expectation Theory of The Global Financial Crisis of 2007 and 2008. Archives of Business Research, 8(6), 118-126. https://doi.org/10.14738/abr.86.8399

Walters, E. T. (2020B). Impact of advancement in technology, false conclusion of real estate bubble, record low mortgage delinquency irresponsible media, U.S. economic policy disaster: Evidence supporting Eddison Walters Risk Expectation Theory of The Global Financial Crisis of 2007 and 2008. International Business Research, 13(7), 224-235. https://doi.org/10.5539/ibr.v13n7p224

Walters, E. T. (2020C). Increase in consumer debt preceding crisis due to advancement in technology, further evidence supporting the idea no real estate bubble existed preceding crisis presented by Eddison Walters Risk Expectation Theory of The Global Financial Crisis of 2007 and 2008: The case for Eddison Walters Modern Economic Analysis Theory. International Business Research, 13(9), 122-122. https://doi.org/10.5539/ibr.v13n9p122

Walters, E., \& Djokic, B. (2019). No real estate bubble preceding global financial crisis: Eddison Walters Risk Expectation Theory of The Global Financial Crisis of 2007 and 2008, Journal of International Business and Economics, 7(2), 1-11. Published by American Research Institute for Policy Development. https://doi.org/10.15640/jibe.v7n2a1 
World Bank.org. (2020). World Bank Database. Retrieved from https://data.worldbank.org

\section{Copyrights}

Copyright for this article is retained by the author(s), with first publication rights granted to the journal.

This is an open-access article distributed under the terms and conditions of the Creative Commons Attribution license (http://creativecommons.org/licenses/by/4.0/). 